\title{
Shock source and intensity: Variables in shock-induced fighting*
}

\author{
MICHAEL J. FOLLICK and JOHN F. KNUTSON $\dagger$ \\ The University of Iowa, Iowa City, lowa 52242
}

\begin{abstract}
Alternating current, direct current, and rectified alternating current shock were compared at four shock intensities to assess differential influences on shock-induced fighting in rats. At higher shock intensities, the data paralleled the Campbell and Masterson (1969) equal aversion function, but at lower shock intensities, differences among shock types with respect to frequencies of shock-induced fighting were obtained. These results suggested that, at lower shock intensities, shock type is a variable in shock-induced aggression research with rats.
\end{abstract}

Electric footshock is among the more frequently employed stimuli in the induction of rat aggression in the laboraty. Both intensity and duration of footshock have been found to be important determinants of shock-induced fighting, with intensity being the more potent determinant (Dreyer \& Church, 1968). Attempts to determine the optimal intensity for the production of shock-induced aggression have resulted in some degree of disparity. Ulrich and Azrin (1962) reported that the optimal shock intensity for the production of fighting was $2 \mathrm{~mA}$. Shocks of lower intensities were reported to lack sufficient aversiveness, and shocks greater than $2 \mathrm{~mA}$ were either described as debilitating or they resulted in competing behaviors. In contrast, Powell, Francis, Braman, and Schneiderman (1969) report $4.0 \mathrm{~mA}$ as the optimal intensity for ind ucing fighting in paired rats, and Creer and Powell (1971) report no differences in fighting using $1.0,2.0,3.0$, and $4.0 \mathrm{~mA}$.

A review of the literature on shock-induced aggression with rats indicates that various types of power supplies have been used to provide the electric shock. Cornsweet (1963) notes that ac shock is superior to dc shock; constant-current ac power supplies have been used by Dreyer and Church (1968), Powell et al (1969), Powell and Creer (1969), Creer and Powell (1971), Ulrich (1967b), and Galef (1970). Other investigators (e.g., Berry \& Jack, 1971; Caggiula, 1972; Hutzell \& Knutson, 1972; Knutson, 1971; Knutson \& Hynan, 1972; Payne, Anderson, \& Murcurio, 1970) have reported using constant-current dc power supplies. In addition, many

\footnotetext{
*This investigation was supported, in part by Biomedical Sciences Support Grant FR-07035 from the General Research Support Branch, Division of Research Resources, Bureau of Health Professions Education and Manpower Training, National Institutes of Health (awarded by The Office of the Vice-President for Educational Development and Research), and, in part, by funds made available by the Graduate College of the University of Iowa. The assistance of Curt Carlson is gratefully acknowledged.

$\dagger$ R equests for reprints should be sent to John F. Knutson, Department of Psychology, The University of Iowa, lowa City,
} Iowa 52242. articles specify the intensity of shock, but fail to specify either the type of shock or the vendor of the shock source.

Campbell and Masterson (1969), using rats in a locomotor task, demonstrated that shock from a constant-current dc source is somewhat less aversive than a shock of the same current level from a constant-current ac source, when both sources were compared to a $150 \mathrm{~K}-\mathrm{ohm}$ fixed-impedance reference source. Based on the resulting Campbell and Masterson (1969) equal-aversion function, it seems possible that the ac and $d c$ shock sources employed in aggression laboratories could influence shock-induced aggression differentially and be functionally related to apparent data differences in the literature. The present study was designed to assess the functional equivalence and comparability of four intensities of ac and dc shock with respect to shock-induced aggression. In addition, because rectified ac (ac rec) shock is used in some laboratories (e.g., Crowell \& Frei, 1972; Crowell, 1973), four intensities of fullwave-rectified ac shock were included for comparison with the ac and dc shock.

\section{METHOD}

\section{Subjects}

One hundred and forty-four 100-day-old experimentally naive male hooded rats from the colony of the Department of Psychology at The University of Iowa served as Ss. The weight of the rats ranged from $265 \mathrm{~g}$ to $330 \mathrm{~g}$, with a mean of $295 \mathrm{~g}$. During the 2 days prior to aggression testing, and for the duiation of the study, animals were individually housed in $9.5 \times 7 \times 7$ in. cages, with free access to food and water. Colony lighting followed an alternating 12-h-light, 12-h-dark schedule

\footnotetext{
Apparatus

The clear Plexiglas fighting chamber was $12.5 \times 9.5 \times 8.0$ in. with a grid floor of .093-in.-diam stainless steel rods spaced 0.5 in. apart, center-to-center. The fighting chamber was positioned in an Industrial Acoustics Corp. $8.0 \times 8.0 \times 7.0 \mathrm{ft}$ sound-attenuating chamber, directly adjacent to an observation window. Illumination was provided by a $100-\mathrm{W}$ light which was located 18 in. above the experimental chamber. Shock duration,
} 

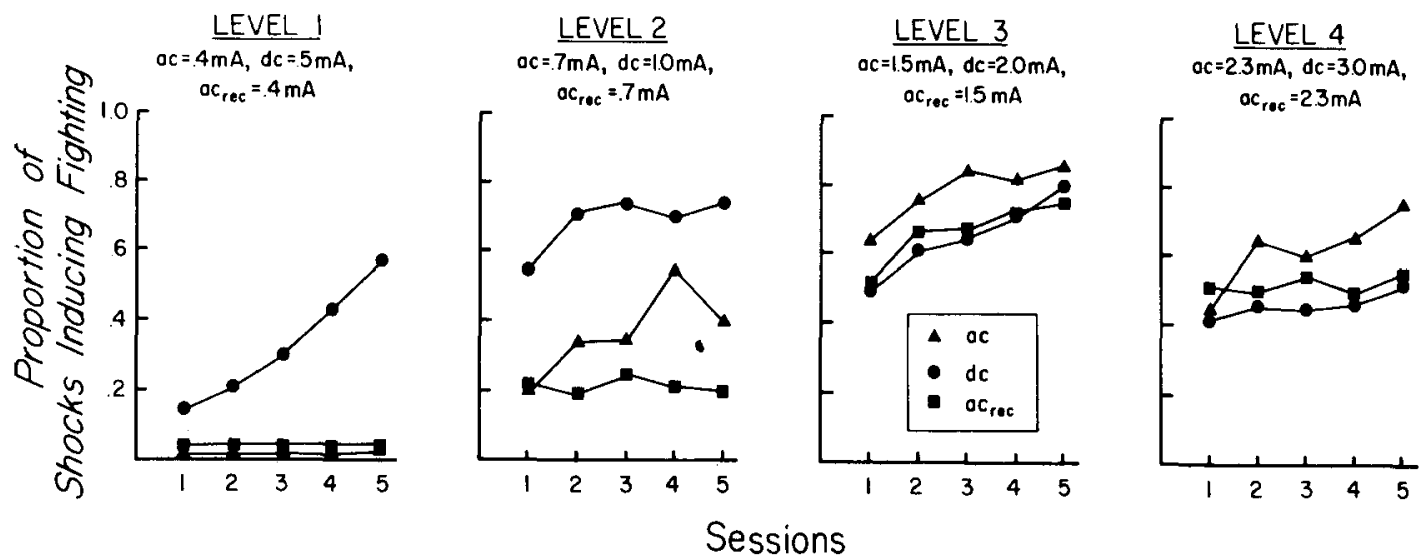

Fig. 1. Mean proportion of shocks ind ucing fighting in each group of rat pairs during each session.

frequency, and the intershock interval were programmed by conventional timers and electromechanical circuitry, and data were recorded on electromechanical counters.

The shocks administered were of three types and were generated by two different constant-current shock sources. The dc shock was provided by a North-Hills (Model CS-111) precision current source. The ac shock was provided by a BRS-Foringer shock generator (Model S6-901), and rectified ac shock was produced by passing current from the BRS-Foringer shock source through a full-wave bridge rectifier constructed of 2.5-A, 1,000-V diodes. Grid shock from each source was scrambled by the same Gerbrands (Model G5820) carbon brush scrambler.

\section{Procedure}

Rats were paired according to weight. Six pairs of animals were randomly assigned to each of 12 different shock-condition groups. Each group received five sessions of shock-induced aggression testing using a single type of shock and a single shock intensity. The ac shock intensities $(.4, .7,1.5$, and $2.3 \mathrm{~mA})$ were chosen as approximately equal to the $\mathrm{dc}$ intensities $(.5,1.0,2.0$, and $3.0 \mathrm{~mA}$ ) on the basis of the equal-aversion function described by Campbell and Masterson (1969). Rectified ac shock intensities $(.4, .7,1.5$, and $2.3 \mathrm{~mA})$ were arbitrarily chosen equal to the ac shock intensities. Shock intensities were calibrated prior to each session. All of the shock intensities for the ac, dc, and ac rec shock sources were determined using a Hewlet t-Packard 3400-A RMS voltmeter across a $1 \%$ precision $150-\mathrm{ohm}$ resistor in series with the power supply, when the scrambler was in operation and a $22 \mathrm{~K}-\mathrm{ohm}$ resistor had been placed across the two grid bars closest to the front of the chamber. After calibration, the $22 \mathrm{~K}$ ohm resistor was removed. The RMS voltmeter, in series with the rats, remained across the 150 -ohm resistor to permit continuous monitoring of the shock delivery.

To assess the current regulating function of the shock sources, fixed resistors approximating variations in rat resistance at the various shock levels used (Campbell \& Teghtsoonian, 1958) were placed across the two grids and RMS voltage drops across the 150 -ohm resistor were measured. At maximum resistance for each intensity, current variation did not exceed $15 \%$ for ac and ac rec, and $5 \%$ for $\mathrm{dc}$.

Each test session consisted of 1000.5 -sec-duration shocks, presented at an intershock interval of $3 \mathrm{sec}$ (onset to onset). The experimental sessions were separated by a period of $24 \mathrm{~h}$, except when Ss sustained tissue damage. To reduce the possibility of infection, lacerated animals were provided a solution of $200 \mathrm{mg}$ of Oxytetracycline $\mathrm{HCl}$ per gallon of water, in lieu of home-cage drinking water, for $48 \mathrm{~h}$ following injury. Injured rats were given sufficient time to heal before aggression test sessions were resumed. Previous experinece in this laboratory has indicated that this procedure does not influence shock-induced aggression in rats.

A trained $O$ recorded a single aggressive response during a shock presentation if the rats lunged at or struck at each other, and produced physical contact by biting or boxing in the stereotyped pattern (cf. Ulrich \& Azrin, 1962). Because nonshocked rats are rarely attacked (Knutson, 1971), and because rats may occasionally emit shock-avoiding postural responses, shock-avoiding responses were recorded for each shock. The RMS voltmeter, across the 150 -ohm resistor in series with the rats, provided an objective means for determining avoidance by both rats because of the $0-\mathrm{V}$ reading produced by an open circuit.

\section{RESULTS}

Avoidance of shock rarely occurred, and it was not systematically related to shock type and intensity. One pair of rats from the 2.3-mA ac group, and one pair from the $2.3-\mathrm{mA}$ ac rec group were discarded due to severe tissue damage suffered by one member of each pair during the fourth session. Extreme heterogeneity of variance resulted from the large number of zero fighting scores in the 0.4-mA ac and ac rec groups, so all Level 1 shock-intensity groups were eliminated from the overall statistical analysis. An analysis of the proportion of presented shocks inducing fighting was accomplished using a repeated-measure analysis of variance based on unweighted means.

Figure 1 shows the mean fighting frequency for each group of rat pairs during each test session. The increase in fighting across sessions was statistically significant $(\mathrm{F}=15.596 ; \mathrm{df}=4 / 172 ; \mathrm{p}<.001) . \quad$ A statistically significant Shock Intensity by Shock Type interaction $(F=8.761 ; \quad \mathrm{df}=4 / 43 ; \mathrm{p}<.001)$ precluded an examination of the main effects of intensity and shock type, and necessitated the examination of simple effects.

Analysis of intensity within shock type indicated that the differences among the three intensities of dc shock did not reach statistical significance $(F=1.98 ; \mathrm{df}=2 / 15$; n.s.). Differences among the three intensities of ac shock did reach statistical significance $(F=5.87 ; \mathrm{df}=2 / 14$; 
$p<.025$ ). Using the Tukey hsd test (Kirk, 1969), an evaluation of mean differences between ac shock groups indicated that Levels 3 and 4 resulted in more fighting than did Level $2(p<.01)$ and that Levels 3 and 4 did not differ significantiy. Differences among the three intensities of ac rec were also obtained $(F=7.20$; $\mathrm{df}=2 / 14 ; \mathrm{p}<.01$ ). Individual comparisons of intensity group means within ac rec shock indicated that Levels 3 and 4 resulted in more fighting than Level $2(p<.01)$ and that Levels 3 and 4 did not differ significantly.

Data were also assessed by testing simple effects among shock types within levels. Level 1 groups were not included in the statistical analysis. Figure 1 shows that the Level $1 \mathrm{ac}$ and ac rec groups displayed virtually no fighting across all sessions. In contrast, the Level $1 \mathrm{dc}$ group displayed some fighting during the first session, and an increase in fighting across all sessions. An analysis of the differences between shock types within each of the remaining shock levels indicated reliable differences within Level 2 only $(\mathrm{F}=8.03 ; \mathrm{df}=2 / 15 ; \mathrm{p}<.005)$. Within that level, the dc shock resulted in more fighting than the ac and ac rec groups, and the ac and ac rec groups did not differ significantly.

\section{DISCUSSION}

The obtained shock type and intensity interaction indicates that the locomotor-based equal-a version function is not directly applicable to the shock-induced aggression paradigm. At the lower levels, the dc shock resulted in grcater fighting than the "equivalent" ac or ac rec shocks, while at higher levels, no differences among shock types were obtained. Thus, the equal-aversion function seems applicable to shock-induced fighting at higher intensities of shock only. In addition, differences between intensities did not obtain at the higher levels, suggesting that the level differences were inadequate and that aggression is a less sensitive measure of aversiveness than lcomotor behavior. Based upon the pain-agression hypothesis (Ulrich, 1967a), aggressive behavior has been used as an index of aversiveness (c.g., Richards \& Rilling, 1972). It has frequently been demonstrated that different behavioral methodologies yield different results in assessments of stimulus aversiveness (e.g., Knutson \& Bailey, 1974; Myers, 1967). When the data of the present study are contrasted with the Campbell and Masterson (1969) data, it seems likeiy that aggression is the more insensitive measure of aversiveness.

The difference between the ac shocks and dc shocks in inducing aggression at low intensities is underscored by a comparison with the results reported by Creer and Powell (1971). In that study, $0.5 \mathrm{~mA}$ ac resulted in virtually no fighting, just as $0.4 \mathrm{~mA}$ ac and ac rec resulted in virtually no fighting in the present study, In contrast, $0.5 \mathrm{~mA}$ dc shock in the present study resulted in considerable attack, far more than $0.5 \mathrm{~mA} \mathrm{ac}$ reported by Creer and Powell (1971).

Creer and Powell (1971) also reported no group differences among $1.0,2.0,3.0$, and $4.0 \mathrm{~mA}$ ac, whereas the present study identified fighting differences associated with smaller intensity differences among the ac groups. This difference between the present study and that of Creer and Powell (1971) could reflect nothing more than statistical power.

The specification of an optimal intensity of shock for use in shock-induced aggression reseurch has been involved in several studies (e.g., Creer \& Powell, 1971; Dreyer \& Church, 1968; Powell et il, 1969; Ulrich \& Azrin, 1962). High-frequency fighting is usually the criterion for optimal intensity, although across-session stability (e.g., Powell et al, 1969) has also been considered. Comparisons among studies indicate optimal intensities ranging from $2.0 \mathrm{~mA}$ (Ulrich \& Azrin, 1962) to $4.0 \mathrm{~mA}$ (Powell et al, 1969). Analyses of such discrepant optimal levels of shock are made difficult by a variety of procedural differences. Both within-S designs (Powell et al, 1969; Ulrich \& Azrin, 1962) and between-S designs (Creer \& Powell, 1971) have been adopted. Because shock history and fighting history influence shock-induced aggression (Powell \& Creer, 1969; Roberts \& Larson, 1967), it is likely that within-S assessments would yield results differing from between-S assessments. Differences in shock type, and variations in determining shock levels, and constancy of shock (cf. Powell et al, 1969) could contribute to differences also. Definitions of the fighting response also vary among laboratories, especially with respect to the inclusion or exclusion of "threat behavior." The specification of an optimal intensity of shock for use in shock-induced aggression research is not likely to emerge from a synthesis of different procedural variations, and data from this experiment do not clearly indicate an optimal intensity.

\section{REFERENCES}

Berry, R., \& Jack, C. The effect of temperature on shock-elicited aggression in rats. Psychonomic Science, 1971, 23, 341-343. Caggiula, A. Shock-elicited copulation and aggression in male rats. Journal of Comparative \& Physiological Psychology, $1972,80,393-397$.

Campbell, B. A., \& Masterson, F. A. Psychophysics of punishment. In B. A. Campbell and R. M. Church (Eds.), Punishment and aversive behavior. New York: A ppleton-Century-Crofts, 1969 .

Campbell, B. A., \& Teghtsoonian, R. Electrical and behavioral effects of different types of shock stimuli on the rat. Journal of Comparative \& Physiological Psychology, 1958, 64, $171-175$.

Cornsweet, T. N. The design of electric circuits in the behavioral sequences. New York: Wiley, 1963.

Creer, T. L., \& Powell, D. A. Effect of repeated shock presenations and different stimulus intensities on shock-induced aggression. Psychonomic Science, 1971, 24, $133-134$.

Crowell, C. R. The role of shock-induced emotionality in the reinforcing effects of response-contingent shock-rate reduction. Unpublished doctoral dissertation, The University of Iowa, 1973

Crowell, C. R., \& Frei, L. A circuit to permit an electronic drinkometer to operate during footshock. Behavior R esearch Methods \& Instrumentation, 1972, 4, 193-194.

Dreyer, P. I. \& Church, R. M. Shock-induced fighting as a function of the intensity and duration of the aversive stimulus. Psychonomic Science, 1968, 10, 271-272.

Galef, B. Stimulus novelty as a factor in the intraspecific pain-associated aggression of domesticated rats. Psychonomic Science, 1970, 18, 21 .

Hutzell, R. R., \& Knutson, J. F. A comparison of shock-elicited fighting and shock-elicited biting in rats. Physiology \& Behavior, 1972, 8, 477-480.

Kirk, R. E, Experimental design: Procedures for the behavioral sciences. Belmont, Calif : Brooks/Cole, 1968 .

Knutson, J.F. The effects of shocking one member of a pair of rats. Psychonomic Science, 1971,22, 265-266.

Knutson, J. F., \& Bailey, M. I. Free-operant escape-avoidance of noise by rats. Journal of the Experimental Analysis of Behavior, 1974 , in press.

Knutson, J. F., \& Hynan, M. T. Influence of upright posture on shock-elicited aggression in rats. Journal of Comparative \& Physiological Psychology, 1972, 81, 297-306.

Myers, A. K. Contradictory evidence for aversion to auditory stimulus resulting from different test methods. Journal of Comparative \& Physiological Psychology, 1967,64, 171-175.

Payne, R., Anderson, D. C., \& Murcurio, J. Preshock-produced alterations in pain-elicited fighting. Journal of Comparative \& physiological Psychology, 1970, 72, 258-266.

Powell, D. A., \& Creer, T. I. Interaction of developmental and environmental variables in shock-elicited aggression. Journal of Comparative \& Physiological Psychology, 1969, 69, 219-225.

Powell, D. A., Francis, J., Braman, M. J., \& Schneiderman, N. Frequency of attack in shock-elicited aggression as a function of the performance of individual rats. Journal of the Experimental Analy sis of Behavior, 1969, 12, 817-823.

Richards, R. W., \& Rilling, M. A versive aspects of a fixed-interval 
schedule of food reinforcement. Journal of the Experimental Analysis of Behavior, 1972, 1972, 17, 405-411.

Roberts, C., \& Larson, C. Shock history and adaptation as parameters of elicited aggression in rats. The Psychological Record, 1967, 17, 425-428.

Ulrich, R. E. Pain-aggression. In G. A. Kimble (Ed.), Foundations of conditioning and learning. New York: Appleton-Century-Crofts, 1967a.

Ulrich, R. E. Interaction between reflexive fighting and cooperative escape. Journal of the Experimental A nalysis of Behavior, $1967 \mathrm{~b}, 10,311-317$.

Ulrich, R. E., \& Azrin, N. H. Reflexive fighting in response to aversive stimulation. Journal of the Experimental Analysis of Behavior, 1962, 5, 511-520.

(Received for publication February 21, 1974; revision received July 5,1974 .) 